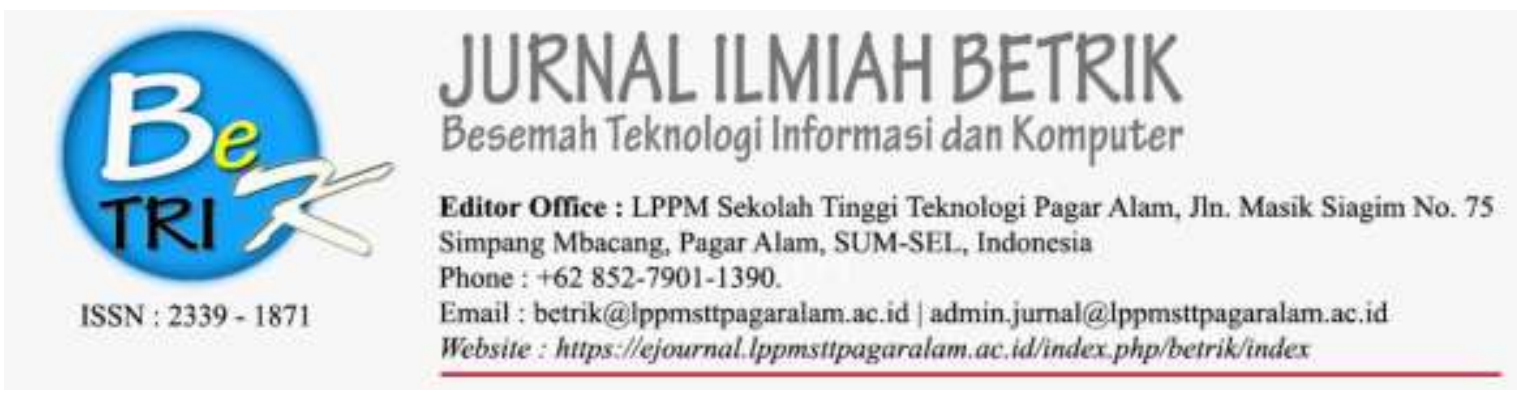

\title{
PERENCANAAN STRATEGIS SISTEM INFORMASI DAN TEKNOLOGI INFORMASI PADA SEKOLAH MENENGAH KEJURUAN NEGERI 2 PAGAR ALAM
}

\author{
Yogi Isro' Mukti
}

\author{
Dosen Program Studi Sekolah Tinggi Teknologi Pagaralam \\ Jln. Masik Siagim No.01 Simpang Mbacang Dempo Tengah Pagar Alam, Kota Pagar Alam. \\ Email : yogie.isro.mukti@gmail.com
}

\begin{abstract}
The development of information technology has increased so much interesting to do research, from a variety of disciplines. This study is flexible means to include all the things, one of which is the business process in an organization, HOW to create an organization that is able to compete. Obviously we need a strategic plan to improve the quality and thus the quality of the organization, what is the purpose of the organization is able to walk properly. In this case also attracted the attention of researchers is to conduct research on the organization of SMK in the city of Pagar Alam from the viewpoint of information systems and information technology. Obviously in this case we need a strategic planning / IT was good so that it can increase the quality of SMK in Pagar Alam, this research using the framework Ward and Peppard with Five Porter analysis, PEST, CSF, SWOT, to support the research.
\end{abstract}

Keywords: Strategic Planning, Ward and Peppard, Proter Five Analysis, PEST, CSF, SWOT

\begin{abstract}
Abstrak : Perkembangan teknologi informasi semakin meningkat sehingga banyak menarik untuk dilakukan penelitian, dari berbagai disiplin ilmu pengetahuan. Penelitian ini sifatnya fleksibel artinya mencakup semua hal, salah satunya adalah proses bisnis dalam suatu organisasi, bagaimna menciptakan organisasi yang mampu bersaing. Tentunya diperlukan suatu perencanaan strategis guna meningkatkan mutu dan kualitas organisasi tersebut sehingga, apa yang menjadi tujuan dari organisasi tersebut bisa berjalan dengan baik. Dalam hal ini juga yang menarik perhatian peneliti adalah melakukan penelitian terhadap organisasi SMK Negeri yang ada di kota Pagar Alam dari sudut pandang sistem informasi dan teknologi informasi. Tentunya dalam hal ini diperlukan suatu perencanaan strategis SI/TI yang baik sehingga bisa meningkatkan mutu dan kualitas SMK Negeri yang ada di Pagar Alam, penelitan ini menggunakan framework Ward dan Peppard dengan analisis Five Porter, PEST, CSF, SWOT, guna mendukung penelitian.
\end{abstract}

Kata Kunci : Perencanaan Strategis, Ward and Peppard, Analisis Five Proter, PEST, CSF, SWOT

\section{PENDAHULUAN}

Pagar Alam merupakan salah satu daerah otonomi yang berdiri sesuai dengan
Undang-undang Nomor 8 Tahun 2001 Tentang

Pembentukan Kota Pagar Alam (Lembaran

Negara Tahun 2001 Nomor 88). Memiliki 
banyak Sekolah Menengah Kejuruan (SMK), baik negeri maupun swasta. Guna meningkatkan mutu dan kualitas serta pembangunan SMK yang ada, sesuai dengan visi Kementrian Pendidikan dan Kebudayaan serta Direktorat Pengembangan SMK, maka perlu adanya suatu perencanaan strategis yang dapat dijadikan acuan, guna pengembangan SMK kedepan.

Saat ini SMK Negeri 2 Kota Pagar Alam belum sepenuhnya menggunakan Teknologi Informasi dan Komputer (TIK) hal ini dikarenakan banyak Faktor-faktor yang mempengaruhi perencanaan strategis SMK Negeri 2 Pagar Alam oleh karena itu perlunya penyediaan perencanaan SI/TI agar Teknologi Informasi Komputer (TIK) pada SMK Negeri 2 Pagar Alam sehingga dapat berjalan dengan baik. Oleh karena pentingnya Perencanaan Strategis SI/TI pada SMK Negeri 2 Kota Pagar Alam ini diharapkan dapat dijadikan usulan dan panduan SMK Negeri 2 Pagar Alam dalam menyusun perencanaan strategis Sistem Informasi dan Teknologi Informasi (SI/TI), yang sesuai dengan visi, misi organisasi. Penelitian ini memberikan ilustrasi atau gambaran dalam merumuskan perencanaan strategis sistem informasi dan teknologi informasi (SI/TI), sehingga memperoleh informasi strategis yang dibutuhkan untuk memantau kinerja pelayanan dan pengembangn organisasi dengan cepat dan mudah.

Guna meningkatkan mutu dan kualitas organisasi SMK Negeri 2 Pagar Alam sehingga berdampak positif terhadap kemajuan dibidang Teknologi Informasi (TI), dan meningkatkan value investasi dan penerapan dibidang Sistem Informasi Teknologi Informasi (SI/TI), maka dirumuskan menyusun perencanaan strategis Sistem Informasi dan Teknologi Informasi (SI/TI) pada SMK Negeri 2 yang ada di Kota Pagar Alam yang bertujuan untuk :

1. Membuat perencanaan kebutuhan teknologi informasi berupa hardware, software dan Sumber Daya Manusia (SDM) yang menunjang dalam proses bisnis

2. Membuat perencanaan strategis sistem informasi dan teknologi informasi (SI/TI) SMK Negeri di Pagar Alam yang terintegrasi sehinggan memudahkan manajemen mengelola sistem informasi yang dibutuhkan

3. Membuat usulan portofolio aplikasi mendatang dan jadwal implementasi perencanaan strategis SI/TI dari solusi SI/TI yang telah dirumuskan yang selaras dengan proses bisnis yang ada di SMK Negeri 2 Pagar Alam

Sehingga penelitian ini dapat dijadikan bahan perencanaan dalam menentukan kebutuhan teknologi informasi berupa hardware, software, dan SDM. Serta diharapkan dapat dijadikan usulan dan panduan SMK Negeri di Pagar Alam dalam menyusun perencanaan strategis Sistem Informasi dan Teknologi Informasi (SI/TI), yang sesuai dengan visi, misi organisasi. 


\section{METODOLOGI PENELITIAN}

\subsection{Desain Penelitian}

Penelitian ini mencoba menggali kebutuhann perusahaan jasa pendidikan dalam merencanakan strategi SI/TI. Perencanaan strategi SI/TI yang dibuat menyesuaikan dengan visi, misi dan tujuan SMK. Adapun desain dari penelitian yang digunakan sebagai acuan dalam menyusun perencanaan strategi SI/TI dengan menggunakan perencanaan strategi model John Ward \& Joe Peppard (2002) :



Gambar 1.Framework Prenencanaan Strategi SI/TI Pada SMK di Pagaralam

\subsection{Alat Analisis}

1. Analisis PEST

Dalam penelitian ini perlu mengidentifikasi faktor-faktor eksternal dalam lingkungan mereka yang bisa berdampak pada operasi organisasi. Banyak hal yang menjadikan organisasi tidak mempunyai kontrol keatas, tetapi implikasi yang perlu dipahami. Sebuah alat yang digunakan untuk identifikasi faktor eksternal adalah PEST analysis, yang dapat digunakan untuk membantu organisasi mempertimbangkan isu-isu politik, ekonomi, sosial, teknologi.

a. P-Politik, Peristiwa politik yang terjadi, monopoli perusahaan Negara, pajak, peraturan perdagangan internasional dan stabilitas pemerintah.

b. E-Ekonomi, Inflasi, peningkatan ekonomi, peredaran uang, harga sumber daya energi seperti listrik dan BBM, peningkatan ekonomi, siklus perdaganagan nasional dan internasional.

c. S-Sosial,Perubahan jumlah penduduk, perubahan gaya hidup masyarakat, tingkat pendidikan, pendapatan masyarakat.

d. T-Teknologi,Pengembangan inovasi terbaru, perpindahan teknologi, penelitian terbaru.

2. Analisis SWOT

Analisis SWOT adalah metode perencanaan strategis yang digunakan untuk mengevaluasi kekuatan (strengths), kelemahan (weaknesses), peluang (opportunities), dan ancaman (threats) dalam suatu proyek atau suatu spekulasi bisnis. Keempat faktor itulah yang membentuk akronim SWOT (strengths, weaknesses, opportunities, dan threats). Proses ini melibatkan penentuan tujuan yang spesifik dari spekulasi bisnis atau proyek dan mengidentifikasi faktor internal dan eksternal yang mendukung dan yang tidak dalam mencapai tujuan tersebut. Analisis SWOT dapat diterapkan dengan cara menganalisis dan memilah berbagai hal yang mempengaruhi 
keempat faktornya, kemudian menerapkannya dalam gambar matrik SWOT, di mana aplikasinya adalah bagaimana kekuatan (strengths) mampu mengambil keuntungan (advantage) dari peluang (opportunities) yang ada, bagaimana cara mengatasi kelemahan (weaknesses) yang mencegah keuntungan (advantage) dari peluang (opportunities) yang ada, selanjutnya bagaimana kekuatan (strengths) mampu menghadapi ancaman (threats) yang ada, dan terakhir adalah bagaimana cara mengatasi kelemahan (weaknesses) yang mampu membuat ancaman (threats) menjadi nyata atau menciptakan sebuah ancaman baru (Wikipedia, 2016)

\section{Analisis Critical Success Factor (CSF)}

Analisis CSF merupakan teknik yang paling efektif dalam melibatkan manajemen senior dalam mengembangkan strategi sistem informasi. Karena CSF secara keseluruhan telah berakar pada bisnis dan memberikan komitmen bagi manajemen puncak dalam menggunakan sistem informasi, yang diselaraskan dengan pencapaian tujuan perusahaan melalui area bisnis yang kritis. (Ward and Peppard : 2002)

CSF adalah faktor-faktor yang menjadi penentu keberhasilan sebuah perusahaan dalam pencapaian tujuannya. (Hoga dan Harisno, 2014). Untuk itu diperlukan suatu ukuran yaitu KPI yang dapat memberitahukan perusahaan sudah sejauh mana kinerja mereka dalam mencapai faktor-faktor keberhasilan (Hoga dan Harisno, 2014).

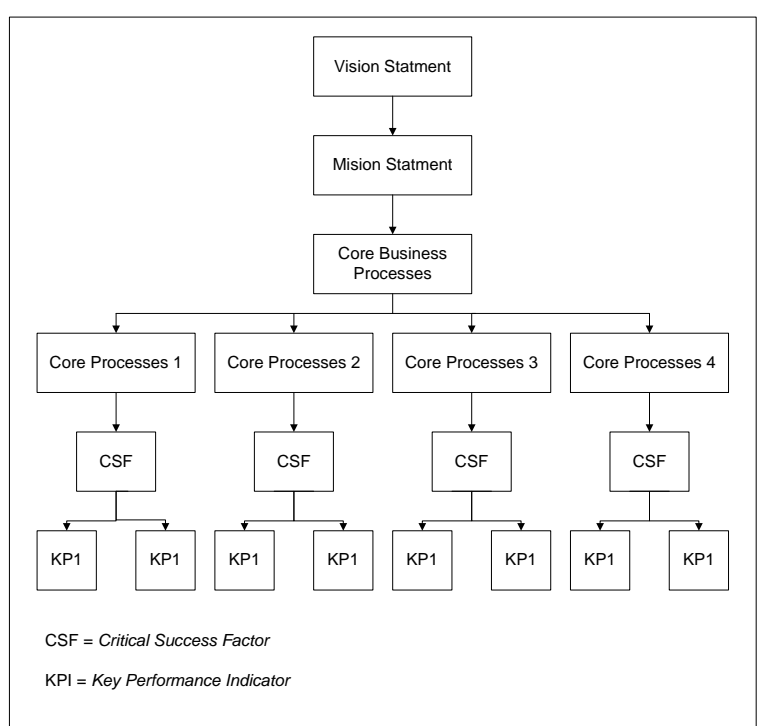

Gambar 2. Bagan CSF

\section{HASIL DAN PEMBAHASAN}

\subsection{Analisis Lingkungan Bisnis SMK Negeri}

Analisis lingkungan bisnis adalah untuk memahami situasi dan kondisi SMK Negeri di Pagar Alam, selanjutnya akan dipetakan dengan menggunakan framework model Ward \& Peppard, untuk mengetahui atau mengidentifikasi akar permasalahan yang ada, yang sedang dihadapi oleh SMK Negeri di Pagar Alam, u

\subsubsection{Analisis Lingkungan Bisnis Ekseternal}

\section{Analisis Porter Lima Ancaman}

Pada hasil analisis porter secara umum kedua SMK memiliki kesamaan yang terangkum dalam bentuk pesaing industri, ancaman produk pengganti, kekuatan pembeli, kekuatan pemasok dan ancaman pendatang baru.

2. Analisi PEST (Politik, Ekonomi, Sosial, Teknologi) 
Berdasarkan data dan observasi penelitian antara SMK Negeri 1 dan SMK Negeri 2 memiliki banyak kesamaan, dimana secara geografis dan kondisi masyarakat hampir sama, dari analisi menggunakan tools PEST. Dimana kondisi SMK Negeri dipengaruhi juga unsur politik, ekonomi, sosial dan teknologi yang selalu mengalami perubahan.

\subsubsection{Analisis Lingkungan Bisnis Internal}

\section{a. Analisi SWOT}

Dari analisis yang dilakukan menunjukan bahwa masing-masing skor untuk ke empat faktor menunjukan Strength skor $=1,906$, untuk faktor weekness memiliki skor $=$ 1,599, sendangkan untuk opportunity skor $=2,088$ faktor threath $=1,282$. Dari masing-masing nilai dapat digambarkan kedalam rumusan matrik SWOT sebagai berikut :

Tabel 1. Rumusan kombinasi strategi matrik SWOT

\begin{tabular}{|c|c|c|}
\hline $\begin{array}{l}\text { Internat } \\
\text { Eksternal }\end{array}$ & Strength & Weakness \\
\hline $\begin{array}{l}\text { Opportunity } \\
\text { (O) }\end{array}$ & $\begin{array}{l}\text { Strategi } \\
(\mathrm{SO}): \\
=1,906+ \\
2,088 \\
=3,994\end{array}$ & 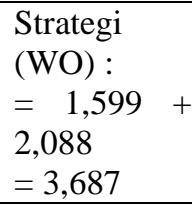 \\
\hline Threat (T) & $\begin{array}{l}\text { Strategi } \\
(\mathrm{ST}): \\
=1,906+ \\
1,282 \\
=3,188\end{array}$ & 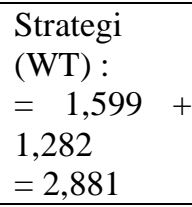 \\
\hline
\end{tabular}

Dari tabel 1 matrik perencanaan kombinasi strategi menunjukan bahwa SMK Negeri 2 yang ada di Pagar Alam perlu memanfaatkan strategi SO, yang mempunyai skor tertinggi yaitu 3,994, selanjutnya diikuti strategi $\mathrm{WO}=3,687$, $\mathrm{ST}=3,188$ dan $\mathrm{WT}=2,881$ adapun masing-masing strategi yaitu mengoptimalkan Sumber Daya Manusia dan Infrastrukturnya.

\section{b. Analisis CSF (Critical Success Factor)}

Kunci sukses keberhasilan SMK Negeri 2 Pagar Alam ini dapat dilihat berdasarkan visi misi, serta tujuan dari SMK 2 Negeri itu sendiri. Dari hasil wawancara peneliti terhadap narasumber pada SMK Negeri 2 Pagar Alam.

Adapun yang menjadi tujuan adalah sebagai berikut :

1) Menjadi Sekolah yang ahli, berkompeten, berprestasi dan berahlak mulia

2) Meningkatkan profesionalisme peserta didik, guru dan pegawai, sesuai dengan bidangnya masing-masing.

3) Menciptakan kerja sama yang saling menguntungkan denga dunia usaha dan dunia industry

4) Mempromosikan Sekolah kepada masyarakat, dunia usaha dan dunia industri.

5) Mengkondisikan Sekolah Pagar Alam menjadi sekolah unggulan dan faforit.

\section{Analisis Lingkungan SI / TI SMK Negeri}

a. Pemanfaat TI Setiap Area Fungsi

Pemanfaatan TI merupakan hal yang penting guna menunjang operasional 
sekolah, sudah tidak dipungkiri lagi peran TI dalam organisasi merupakan alat vital. Manajemen TI yang baik merupakan hal positif bagi perkembangan organisasi. Di SMK Negeri 2 yang ada di Kota Pagar Alam pemanfaatan TI sudah berjalan cukup baik hal ini bisa dilihat dari penggunaan TI yang ada untuk menunjang administrasi dan proses belajar bagi para siswanya.

b. Sarana dan Prasarana

1. Kondisi Hardware (Perangkat Keras)

Adapun kondisi perangkat keras yang rata-rata di pakai dalam mendukung operasional sekolah yang ada pada SMK 2 Negeri Kota Pagar Alam bervariasi, untuk personal computer (PC) yang digunakan mulai dari prosesor generasi dual core,core 2 duo sampai dengan core i3. Untuk peralatan mencetak data rata-rata menggunakan printer canon IP 2770, sedangkan untuk infrastruktur jaringan menggunakan modem speedy dan modem GSM

2. Kondisi Perangkat Lunak (Software)

Saat ini perangkat lunak yang ada merupakan perangkat lunak yang umum di pakai. Dalam menunjang kegiatan administrasi opersaional sekolah aplikasi yang digunakan bersifat umum, untuk mengelola teks dan data menggunakan Microsoft Office dan untuk searching menggunakan web browsermozilla firefox, internet explorer, dan google chrome.

3. Infrastruktur Jaringan

4. Untuk infrastruktur jaringan sendiri SMK Negeri 2 sudah mendapatkan akses internet yang cukup baik dengan belangganan dengan PT. Telkom, dengan kapasitas bandwith up to $1 \mathrm{Mbps}=$ 1024 Kbps. Untuk implementasinya sendiri masih belum maksimal, hal ini dikarenakan akses internet hanya sebatas ruang kantor. Untuk siswa sendiri belum dapat menikmati akses internet dari sekolah guna mendukung dalam proses belajar, sehingga harapan kedepan dapat ditingkatkan lagi dengan penambahan kapasitas bandwith sehingga seluruh kebutuhan akan internet bagi siswa dapat teratasi.

\subsection{Menentukan Strategi SI / TI SMK Negeri di Pagar Alam}

\subsubsection{Strategi Bisnis}

Berikut inti dari strategi bisnis yang tengah akan dilaksanakan.

a. Mengembangkan infrastruktur ICT (Information and Communication Technology) yakni dengan memperbaiki infrastruktur jaringan dengan prioritas agar dapat digunakan untuk menunjang 
penggunaan dan kebutuhan sistem informasi dan teknologi informasi pada masa yang akan datang.

b. Tingkatkan bandwidth untuk akses internet untuk menunjang penggunaan dan kebutuhan sistem informasi dan teknologi informasi pada masa yang akan datang.

c. Mengembangakan website Sekolah untuk setiap program keahlian yang ada, hal ini berfungsi untuk memberikan informasi yang diperlukan siswa dan pihak-pihak lain yang memerlukan dan sebaliknya ada aturan khusus/panduan (user guide) yang mengatur tentang website untuk program keahlian.

d. Mengembangkan SISFO sekolah sehingga dapat mendukung informasi strategis dan pengembangan program-program aplikasi lainnya yang dianggap penting, SISFO sekolah yang perlu dikembangakan yakni Sistem informasi Akademik, Sistem informasi kepegawaian, Sistem Informasi Absensi, e-learning.

e. Pembangunan Aplikasi-Aplikasi untuk strategi SI/TI dimasa yang akan datang.

\subsubsection{Strategi Manajemen}

Tabel 2. Strategi Manajemen

\begin{tabular}{|c|c|c|c|}
\hline No & Strategi & Aktifitas & $\begin{array}{c}\text { Target } \\
\text { Aplikasi }\end{array}$ \\
\hline 1 & $\begin{array}{l}\text { Kualitas } \\
\text { SDM }\end{array}$ & $\begin{array}{l}\text { Melaksanakan } \\
\text { pelatihan, } \\
\text { training, dan } \\
\text { workshop }\end{array}$ & $\begin{array}{l}\text { SI } \\
\text { kepegawaian } \\
\text { (Jangka } \\
\text { pendek/panj } \\
\text { ang) }\end{array}$ \\
\hline
\end{tabular}

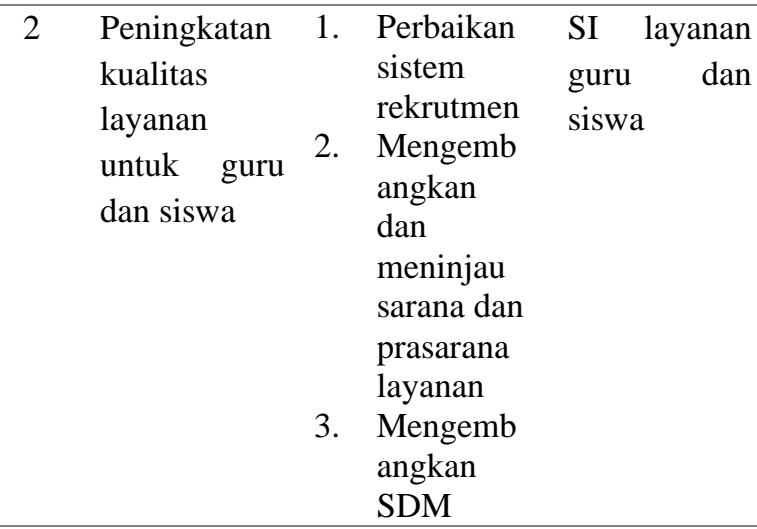

\subsubsection{Strategi Teknologi Informasi dan}

\section{Strategi Sistem Informasi}

Penentuan perencanaan strategi ini di dapat dari analisis yang dihasilkan, memfokuskan anggaran untuk membangun infrastruktur SI/TI yang terintergrasi. Kebutuhan SI/TI yang diperlukan sesuai dengan kebutuhan pada Sekolah Menengah Kejuruan. Diantaranya :

\section{Aplikasi Strategis}

Aplikasi yang sangat kritis untuk keberhasilan Sekolah dimasadatang,diperlukanuntuk inovasiberkelanjutan,integrasivertikal, danmemberikannilaitambah dikelompokkansebagaiaplikasistrategi S. AplikasiPotensiTinggi Aplikasiyangmungkinpentinguntukkeb erhasilanSMK Negeri 2 Pagar Alamdi masadepan,danbiasanyadiperlukan untukrisetdan perencanaan proses, integrasiminimal, dan pengendalian biayadisebut aplikasipotensitinggi.

Tabel3 DaftarAplikasi PotensiTinggi

\begin{tabular}{|c|c|c|}
\hline $\mathrm{N}$ & Kebutuhan Sistem & Keterangan \\
\hline o & Informasi & \\
\hline 1 & Kemudahanakses & $\begin{array}{l}\text { Meningkatkankuantit } \\
\text { as dankualitas }\end{array}$ \\
\hline
\end{tabular}




\begin{tabular}{|c|c|c|}
\hline & $\begin{array}{l}\text { Intranet dan } \\
\text { Internet }\end{array}$ & komunikasi \\
\hline 3 & $\begin{array}{l}\text { Sistemmonitoringki } \\
\text { nerjaSIM }\end{array}$ & $\begin{array}{l}\text { Meningkatkankuantita } \\
\text { s dankualitas } \\
\text { kinerjaSistemInforma } \\
\text { siSekolah }\end{array}$ \\
\hline 4 & $\begin{array}{l}\text { Otomatisasiproses } \\
\text { pelayanan } \\
\text { jasapendidikan }\end{array}$ & Perlusistemon-line \\
\hline 5 & $\begin{array}{l}\text { Penyediaan } \\
\text { informasisecara } \\
\text { Online }\end{array}$ & $\begin{array}{l}\text { Promositanpa batas } \\
\text { waktu dan tempat }\end{array}$ \\
\hline 6 & AplikasiWeb & $\begin{array}{l}\text { Mendukung } \quad \text { basis } \\
\text { teknologi intranet } \\
\text { daninternet }\end{array}$ \\
\hline
\end{tabular}

2. Adapun perencanaan infrastruktur yang di usulkan adalah sebagai berikut

1) Perangkat Keras (Hardware)

Perangkat keras komputer yang umum dipakai untuk pelaksanaan administrasi adalah minimal 10 buah, dan untuk kegiatan pembelajaran untuk masing-masing laboratorium dibutuhkan 30 PC.

2) Perangkat Lunak (Software)

Aplikasi-aplikasi yang ada umumnya dikembangkan secara bersama-sama oleh para sistem analist dan programmer yang berada di Biro Sistem Informasi.

3) Sistem Operasi

Sistem operasi utama yang digunakan adalah Microsoft Windows 7 (Aplikasi Office
Automation, E-mail, Aplikasi

Internet, Linux untuk PC server).

4) Infrastruktur Jaringan

Agar akses jaringan lebih meningkat maka direkomendasikan adalah pembuatan jaringan LAN dilingkungan Sekolah secara keseluruhan yang mana dapat menjangkau seluruh ruangan akan sangat baik untuk dapat diterapkan dimasa yang akan datang Seperti ditunjukan pada gambar berikut.

3. Sumber Daya Manusia (SDM)

Guna terlaksananya penggunaan sistem informasi dan teknologi informasi yang baik, ini tentunya membutuhkan SDM yang baik pula, dengan memberikan pelatihanpelatihan kepada pegawai dan guru TIK yang akan mengoperasikan perangkat teknologi.

\subsection{Portofolio Aplikasi}

Dari hasil analisis yang dilakukan maka dibuatlah portofolio aplikasi dengan mengacu pada pendekatan Ward and Peppard.

Tabel 4. Portofolio Sistem Informasi \& Aplikasi masa yang akan datang

\section{Strategis}

\section{HIGH POTENSIAL}

- Redesign Infrastruktur

- Pembuatan dan jaringan komputer

- E-learning Pengembangan $E$ -

- Sistem Informasi Magang

- Web Conferecing

- Repository untuk Tracing Alumni

- SISFO Sekolah

- Sistem Informasi

- Website SMK Negeri Pagar Alam Manajemen Aset 
System

OPERASIONAL KEY

Support

Adapun rencana infrastruktur jaringan pada SMK Negeri 2 di Kota Pagar Alam, dengan mengacu kepada kebutuhan dan teknologi yang ada ditunjukan gambar berikut :

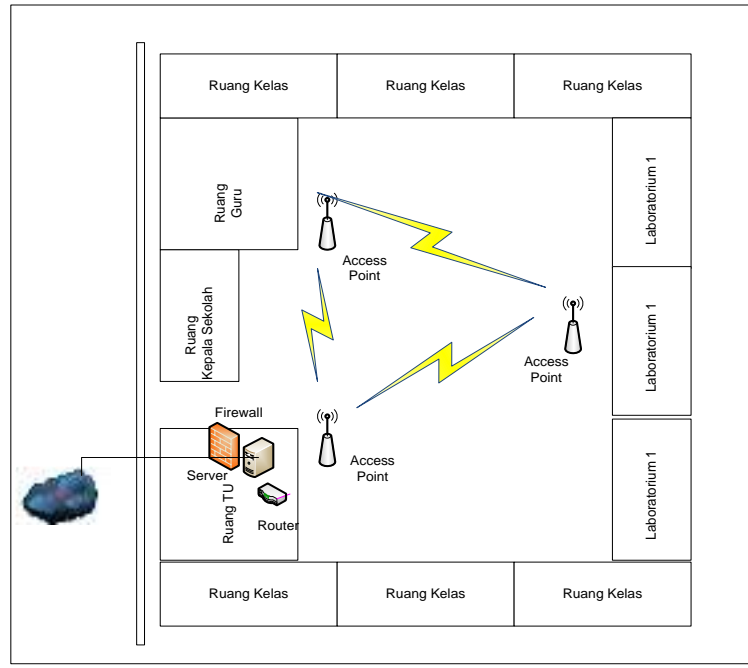

Gambar 3. Rencana Infrastruktur jaringan

SMK Negeri 2 di Pagar Alam

\subsection{Rencana Implementasi}

Adapun rencana implementasi berisi pengkoordinasian dan penjadwalan tugas yang akan dijalankan tim implementasi, dalam hal ini SMK Negeri yang ada di Kota Pagar Alam. Rencana implementasi dibai dua yaitu Jangka Pendek (2013-2017) dan Jangka Panjang (2018-2022) untuk mengimplementasikan solusi Strategis SI/TI dari hasil analisis yang dibuat.

Tabel 5. Rencana Strategis SI/TI Jangka Pendek (2013-
2017)

\begin{tabular}{|c|c|c|c|c|c|c|}
\hline \multirow[t]{2}{*}{ No } & \multirow[t]{2}{*}{ Regiatan } & \multicolumn{5}{|c|}{ Tahm } \\
\hline & & 2013 & 2014 & 2015 & 2016 & 2017 \\
\hline 1 & $\begin{array}{l}\text { Membangun Ulang Infrastrittur } \\
\text { Jaringan }\end{array}$ & & & & & \\
\hline 2 & $\begin{array}{l}\text { Pengembangan Website Sekdah } \\
\text { - Website Program Keahlian } \\
\text { - Website Organisavi siswa }\end{array}$ & & & & & \\
\hline 3 & $\begin{array}{l}\text { Sundarisasi Sarana dan prasarana dan } \\
\text { segi Hardwure dan Sofitware dan Sistem } \\
\text { Aplikasi untuk memudahkan } \\
\text { pemeliharaan sarana. }\end{array}$ & & & & & \\
\hline 4 & Kelas E-leaming & & & & & \\
\hline 5 & $\begin{array}{l}\text { Pembuatan Aplikas SISFO } \\
\text { - Sistem Informasi Abdemik } \\
\text { - Sistem Informasi Nagang } \\
\text { - Sistem Informasi mangiemen asset. }\end{array}$ & & & & & \\
\hline 6 & Disaster Recovery System & & & & & \\
\hline 7 & Repository Tracing Alumni & & & & & \\
\hline
\end{tabular}

Tabel 6. Rencana Strategis SI/TI Jangka Panjang (2018-2022)

\begin{tabular}{|c|c|c|c|c|c|c|}
\hline \multirow[t]{2}{*}{ No } & \multirow{2}{*}{  } & \multicolumn{5}{|c|}{ Taliue } \\
\hline & & 2018 & 2019 & 2020 & 2021 & 2022 \\
\hline 1 & Penind datan Lom man TIK & & & & & \\
\hline$\frac{7}{2}$ & 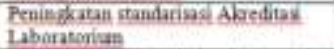 & & & & & \\
\hline 3 & 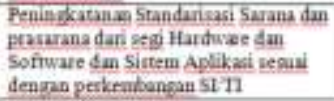 & & & & & \\
\hline 4 & $\begin{array}{l}\text { Peroustakan yars } \\
\text { herget filat terakteditas }\end{array}$ & & & & & \\
\hline 5 & Penin katan loyanen E-tecrning & & & & & \\
\hline 6 & $\begin{array}{l}\text { Penindsaban Lyanan Sitem loformal } \\
\text { Sekstah }\end{array}$ & & & & & \\
\hline
\end{tabular}

\section{SIMPULAN}

Berdasarkan analisis internal dan eksternal pada SMK Negeri 2 Kota Pagar Alam dapat disimpulkan beberapa hal.

1. Berdasarkan data analisis Five Factor dan PEST didapatkan hasil bahwa peran pemerintah daerah terhadap sekolah sangat berpengeruh.

2. Denganadanyakerangkakerjaperenc anaanstrategis SI/TI,pihak SMK Negeri 2 di Pagar Alam dapatmengetahuifaktor-faktor yangdiperlukandalammengembang kansuatuteknologidansisteminform asi yang selarasdenganrencanastrategibisnis. Faktor- 
faktorpentingtersebutdapatdilihatda

rihasilanalisisCSF, SWOT, PEST, yang

dapatdilakukanterhadapstrategidan model bisnis SMK Di kota Pagar Alam

Untuk meninak lanjuti hasil penelitian, disarankan beberapa hal sebagai berikut :

1. Memperbaiki infrastruktur yang ada di SMK di Pagar Alam

2. Memperbaiki tata kelola manajemen IT

\section{DAFTAR PUSTAKA}

Aef Herosandiana, 2014, Jurnal "Perencanaan

Strategis Sistem Dan TeknologiInformasi

Di Sekolah Tinggi Ilmu Kesehatan 'Aisyiyah Bandung,',Unikom

Amin Mustagfirin, 2014, Garis-Garis Besar Pembinaan SMK Tahun 2014, Dirjen

Pembinaan SMK

Anang Tjahjono, 2011, Garis-Garis Besar Pembinaan SMK Tahun 2011, Dirjen

Pembinaan SMK

Jogiyanto, HM. (2005) Sistem Informasi Strategik. Edisi 2. ANDI, Yogyakarta

Jogiyanto, HM. (2005). Sistem Informasi Strategik. Edisi 1. ANDI, Yogyakarta

Karman Joni, 2013, Jurnal "Perencanaan Strategis Sistem Informasi Pada SMK Yadika Lubuk Linggau”, Universitas Bina Darma
Masakim Andi, 2011, Jurnal "Evaluasi Dan Pengembangan Model Rencana Strategis Smk Negeri 1 Batam”, Universitas Negeri Padang

Saragih, Hoga, Harisno.(2014), Rencana Strategis Teknologi Informasi (IT) dan Sistem Informasi (IS) Pada Proses Bisnis Perusahaan.GRAHA ILMU, Yogyakarta

Suryo, Sudaryono, Untung, 2011,Teory and application of IT Research, Andi, Yogyakarta.

Ward, John, Peppard, Joe. (2002). Strategic Planning For Information System. 3rd Edition. John Willey \& Sons, Buffins Lane, Chichester 